\title{
Activity Based Teaching Learning: An Experience
}

\author{
Ujwala Patil $^{1}$, Suneeta V. Budihal ${ }^{2}$, Saroja V. Siddamal ${ }^{3}$, Uma K. Mudenagudi ${ }^{4}$ \\ 1,2,3,4 Department of Electronics and Communication \\ BVBCET, Vidyanagar, Hubli-580031 \\ ${ }^{1}$ ujwalapatil@bvb.edu
}

\begin{abstract}
The paper presents activity based teaching learning for undergraduate students. This also gives the analysis of the effectiveness of these activities. The objective of proposed pedagogical practice is to enhance the course learning, beyond the traditional mode. In the traditional mode of teaching the course was not able to make a positive impact on learning. This is because of monotonous lecturing and absence of activities.Activity Based Teaching Learning (ABTL) is an effort to overcome the limitations of traditional mode of course delivery. Progressive pedagogical models are used for the enhancement of course learning. To meet the objective different activities are designed and practiced along with class room teaching. The frame work includes teaching through games in Digital Communication course for $6^{\text {th }}$ semester Electronics and Communication Engineering (ECE) students and worksheets in Basic Electronics for $\mathrm{I}^{\text {st }}$ year students. In the proposed approach, the active learning provides more opportunities to learn beyond the classroom teaching.Effectiveness of these activities is assessed through academic performance.
\end{abstract}

Keywords: Activity based learning, game based learning, worksheet.

\section{Introduction}

The paper address the in-depth learning in a set of courses like basic electronics in first semester of all disciplanes and digital communication for sixth semester in Electronics and Communication engineering program, throughactivity based learning. Traditional mode of course design and classroom delivery includes chalk and talk for theorotical concepts and tutorials, supported by set of experiments. However these activities did not focus the students with different learning styles and failed to enhance their course learning. In most cases course projects, mini projects, minor projects and capstone projects carried out throughout the programme to evaluate the attainment of student outcomes $a$ to $k$, in an outcome based education framework proposed in ABET and NBA $[1,2,3,4]$.

It is a real challenge to make the students strong in their theoritical concepts to carry out projets. To facilitate this project based approach, learning through activities is practiced in the lower semesters of engineering programme. These issues are addressed by redesigning the curriculum, Adopting activity based pedagogical teaching learning practices. The framework of pedagogical activities designed and practiced in teacing learningincludes several activities: mid lecture wakeup activities, game based learning, worksheets, simulations, one minurte papers, group discussions, hourly plans, think pair and share, case studies, implementation assignments, quizes etc. In this paper few activities are identified and practiced. Worksheets activity is carried out for first year students in Basic Electronics course and game absed learning is practiced in Digital Communication course for sixthsemester students of ECE, to strengthen the course learnung beyond the traditional teaching.

The paper demonstrates:

- Indepth learning in two courses using worksheetand game based approach as ABTLpedagogicaltool..

- Effectiveness of the activities practiced in learning of the course and continous improvement and curriculum modifications.

The frame work of ABTL component is discussed in Section 2. Implementation of ABTL is discussed in Section 3. Conclusions are provided in Section 4.
Ujwala Patil ${ }^{1}$

${ }^{1}$ Department of Electronics and Communication BVBCET, Vidyanagar, Hubli-580031

${ }^{1}$ ujwalapatil@bvb.edu 


\section{The Effective Learning Framework}

The main idea of the frame work shown in Figure 1 is that, effective teaching and learning techniques lead to student satisfaction and motivation to learn when properly supported by a positive learning environment.

\section{A. The Proposed Framework}

The proposed framework consists of four main components:

1. Strategies: Use of different student-centered techniques to support and enhance learning.

2. Roles: Assigning roles and responsibilities to all the stakeholders to ensure their active participation and collaboration.

3. Assessment: Assessment and evaluation methods to measure monitor and promote learning.

4. Environment: Effective learning environment both inside and outside the classroom.

\section{B. Strategies for Effective Learning}

Effective learning needs an interactive classroom environment to motivate and encourage students. Such an environment requires flexible and adaptable teaching strategies to support and develop student's learning potential. Student-centered learning techiques can significantly increase student learning, motivation and their ability to think critically and creatively [6].

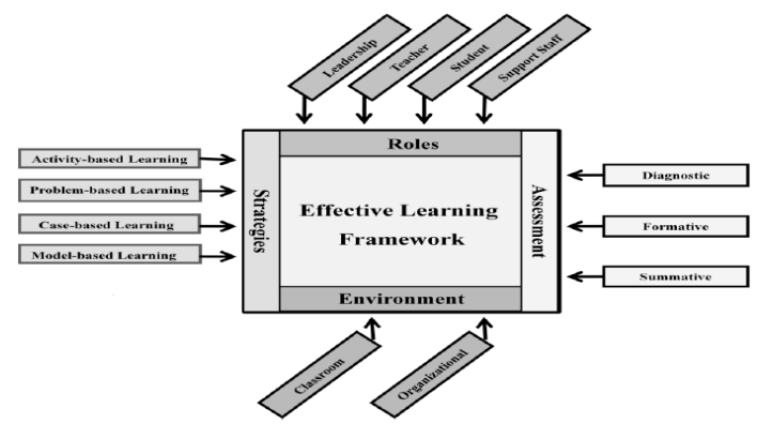

Fig. 1: The Student-centered Effective Learning Framework

(Source 2013 ISSN: 2309-3951, 2014)

\section{Activity Based Learning}

Activity-based learning is based on effective studentteacher interaction. Active learning encourages students to inquire, explore, experiment, collaborate and experience the joy of learning [7]. In this technique the role of teachers shifts from that of delivering knowledge to that of facilitating and motivating [8].

\section{A. Learning Through Worksheet}

The objective of the engineering education is to train the students to apply their knowledge to solve problems in societal context. Different pedagogical activities are practiced toward this during teaching learning process. Project based teaching learning is one of the proven practices in engineering education, and is effective once the competency is built to apply the theoretical concepts to solve engineering problems. The challenge is to cater the students with different learning abilities towards this objective. The homemade worksheets are used to teach any subjects and can be used for any age students [12]. Activity based learning through worksheet is used to facilitate project base learning by strengthening the fundamental concepts during classroom teaching.

1) Scope: Work Sheets for engineering students:The worksheet activity is extensively used in tersery education to improve their linguistic and mathematical abilities. This paper demonstrates the ABTL using worksheets practiced for first year under graduate students.

The benefits of this pedagogical frame work are:

1. It provides interactive classroom environment.

2. The course instructor can break the monotony of the classroom teaching using this activity.

3. The students are allowed to correct their early missteps.

4. The presentation skills are monitored and corrected regularly.

5. Peer learning by think pair and share is possible.

6. The students are motivated to think beyond the typical pattern of evaluation.

7. The positive reinforcement motivates the student improve.

8. The immediate feedback is used to refine the concept dependent teaching technique.

\section{1) Design and practice of work sheet activity:}

The objective of the ABTL is to build the competency to solve real engineering problems. The challenge is to design an activity to focus students with different ability and learning styles. The worksheet activity is practiced to meet the objective. Students are informed about the theme and the expectation of the worksheet in advance and the theme based worksheets are designed by the course instructor and practiced in the classroom. The time spent for this activity is either first $30 \mathrm{~min}$ of the class, discussion on the performance and participation is continued for next $30 \mathrm{~min}$. Most of the time student is monitored and corrected individually,worksheets are designed for group activity also.

2) Difference between normal assignment and worksheet: The worksheets are theme based, it could be to focus mathematical concept, or to improve writing and analysis skill. The Table 1 demonstrates the difference between the normal assignment used in the conventional teaching method and the theme based worksheet designed in this framework.

Table 1: Difference Between Normal Assignment And Worksheet 


\begin{tabular}{|l|l|l|l|}
\hline $\begin{array}{l}\text { Sl. } \\
\text { no }\end{array}$ & $\begin{array}{l}\text { Normal } \\
\text { assignment }\end{array}$ & $\begin{array}{l}\text { Designed } \\
\text { Worksheet }\end{array}$ & Theme is \\
\hline 1 & $\begin{array}{l}\text { Write the } \\
\text { axioms and } \\
\text { postulates of } \\
\text { Boolean } \\
\text { algebra }\end{array}$ & $\begin{array}{l}\mathrm{A}+\_ \text {A } \\
\mathrm{A}+\text { A }\end{array}$ & $\begin{array}{l}\text { To improve } \\
\text { Logical } \\
\text { thinking }\end{array}$ \\
\hline 2 & $\begin{array}{l}\text { Show how } \\
\text { opamp can be } \\
\text { used as an } \\
\text { integrator. }\end{array}$ & $\begin{array}{l}\text { What is the } \\
\text { output of the } \\
\text { following } \\
\text { circuit. }\end{array}$ & $\begin{array}{l}\text { Logical and } \\
\text { mathematical }\end{array}$ \\
\hline
\end{tabular}

3) Effectiveness of the activity:The ABTL using worksheet is practiced and the effectiveness is measured using academic performance of the students as well as using the student's feedback. The Figure 2 shows the influence of the activity on the student performance. The workshop activity for first year students is practiced after minor-1. In minor-1 the student performance was very poor. As a remedial strategic planning ABTL using worksheet is designed and practiced. The performance in minor 2 is improved considerably.

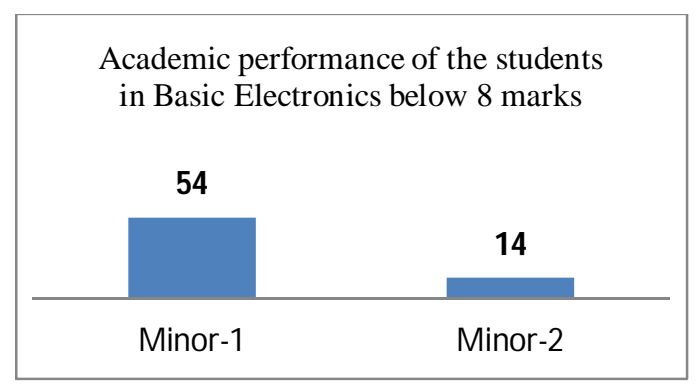

Fig.2: Academic Performance

The effectiveness is analysed using the students feedback also. The feedback questions framed by the instructor are:

1. Activity motivates to apply theoretical knowledge to solve given problem?

2. Activity is relevant in particular course/concept?

3. The worksheets are beyond typical pattern of evaluation.

The Figure 3 reflects the student feedback for this activity. The analysis is done on 1 to 3 scale, 3 being the strongly agree, 2 being the moderately agree and 1 indicates disagree. $85 \%$ of the students strongly agreed that they got motivated take up project based learning by applying theoretical knowledge to solve given problem. $95 \%$ of the students agreed that the design of the worksheet was relevant. $90 \%$ of the students found the worksheets were beyond typical pattern of evaluation. Worksheet is used as an effective pedagogical tool in ABTL. The competency towards the project based learning is achieved.

\section{B. Learning Through Games}

Educational games have become popular in the academic community recently. Educational games can be used to enhance the learning experience by improving student's motivation and engagement. The integration of games in the learning process requires involvement of instructors in the development process to enhance the learning [10].

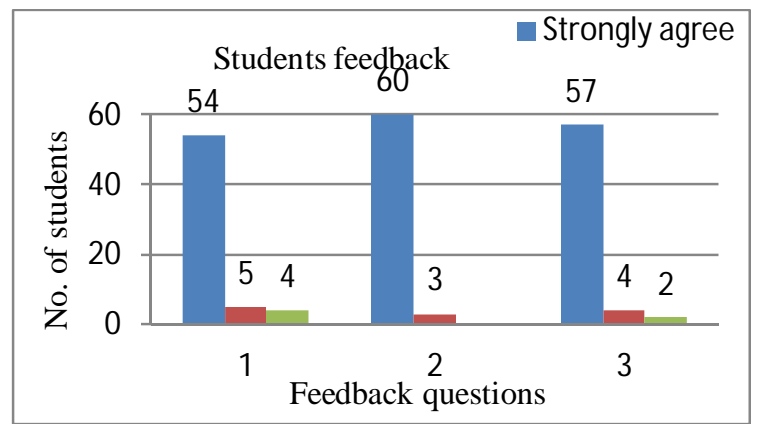

Fig. 3: Students Feedback

1) Scope: Game basedlearning for engineering students: The games are the activities attracting any class of students. The monotonous teaching and learning, limits the learning span of a student. This paper demonstrates the ABTL using games practiced for sixthsemester under graduate students of ECE. The benefits of this pedagogical frame work are:

1. It provides interactive classroom environment.

2. It provides scope for group discussions and thinking beyond the curriculum.

3. The presentation skills are improved.

4. Peer learning by think pair and share is possible.

5. The students are encouraged to apply the theoretical concepts to real time scenarios.

6. The immediate feedback is used to fill the gap of

7. teaching and learning. 


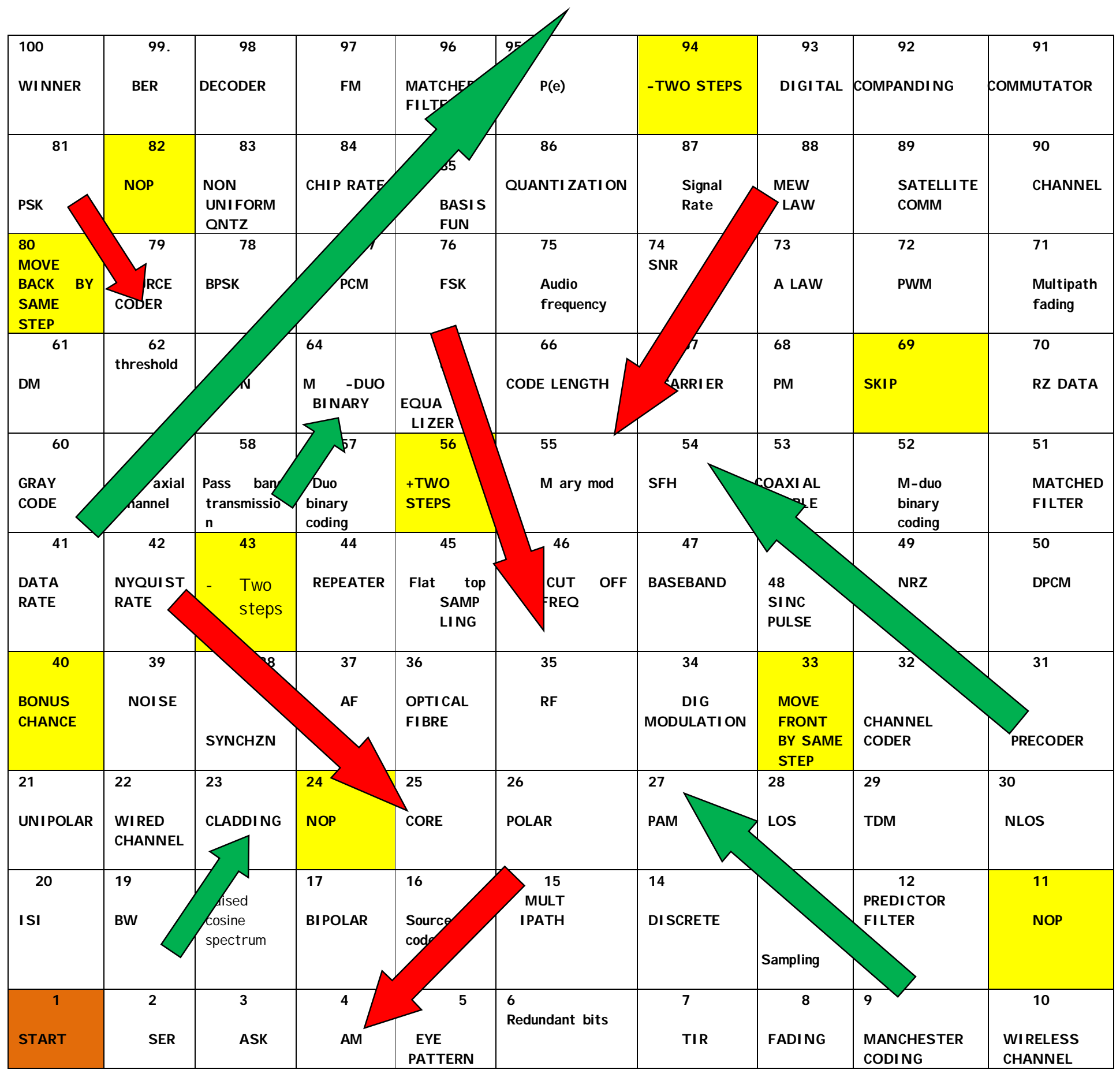

Fig. 5: Templatefor Snake and Ladder Game

2) Design and practice of game based approach:Game based approach resembles snake and ladder game as shown in Figure 5. This activity was designed for $6^{\text {th }}$ semester ECE students in Digital Communication course. To conduct this activity $85 \%$ of the course content needs to be completed. Hence this was scheduled typically after minor II. For the student to activity participate acceptation of the game are informed well in advance. Class of 60 students is grouped into two of 30 each.Digital dice and timer are used as game components.

Toscore the face value points of the tossed dice the second group has to answer the question posed by the first group on the topic of respective grid in the scheduled time. The winning group was rewarded. 
3) Effectiveness of the activity: As the activity is conducted after minor II, the students could revise thoroughly $85 \%$ on the course content. This led to improved preparation for the SEE. Reading wasexhaustive so as to pose difficult question to the opponent team. This activity helped the course instructor to identify and bridge the gap in the classroom teaching. The effectiveness is analysed using the student's feedback as shown in Figure 4.

The feedback questions framed by the instructor are:

1. Activity motivates to strengthen theoretical knowledge.

2. Activity helped them to get connected to the real time scenarios.

3. Activity helped to prepare well for SEE.

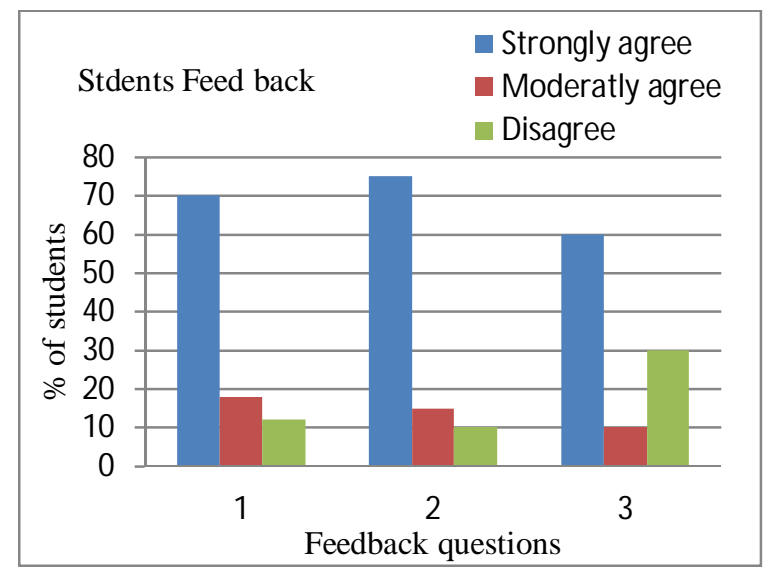

Fig. 4: Students feedback

\section{Conclusion}

The activity based teaching learning for undergraduate students is demonstrated in this paper. The effectiveness of the activities in this framework is also discussed. The analysis shows the enhancement in the course learning beyond the conventional teaching through ABTL. The ABTL found effective in improving the academic performance as well as bridging the gap between the teoratical concepts and real time senarioes.

\section{References}

[1]Accreditation Board for Engineering and Technology (ABET). (2001, Nov). Engineering Criteria 2000: Criteria for Accrediting Engineering Programs, Effective for Evaluations During the 2002-2003 Accreditation Cycle, Baltimore,MD.http://www.abet.org/images/Criteria/200203EACCriteria.pdf.

[2] http://www.nba-aicte.ernet.in/manual.html

[3]Bradley Univ., Elect. Comput. Eng. Dept. (2002, Aug.) Capstone project: Evaluation relative to professionallevel http://cegt201.bradley.edu/ gld/prof_cap.html

[4] Richard M. Felder, Rebecca Brent, "Designing and Teaching Courses to Satisfy the ABET Engineering
Criteria", Journal of Engineering Education, January 2003. 92 (1), 7-25.

[5] Stiggins. R. J. (2002). Assessment crisis: The absence of assessment for learning. Phi Delta Kappan, 83(10), 758765.

[6] Paterson, A. S., Jackson, W. J., Grieve, A. P., \& Paterson, A. S. (2012). The Enhancement of Generic Competencies through the Application of Student Centred Learning: The Students Perspective (No. 1201). Accountancy Research Group, Heriot Watt University.

[7] Brooks, D. W., Nolan, D. E., \& Gallagher, S. M. (2001). Web-teaching: A guide to designing interactive teaching for the World Wide Web (Vol. 9), Springer.

[8] Keengwe, J., Onchwari, G., \&OnChwari, J. (2009). Technology and student learning: Towards a learnercentered teaching model. AACE Journal, 17(1), 11-22.

[9] Bloxham, S., and West, A., "Understanding the rules of the game: Marking peer assessment as a medium for developing students'conceptions of assessment", Assessment and evaluation in highereducation, 29, 6, 2004, 721-733.

[10] Torrente, J., Del Blanco, Á., Marchiori, E. J., Moreno-Ger, P., \&Fernández-Manjón, B. (2010, April). Introducing educational games in the learning process. In Education Engineering (EDUCON), 2010 IEEE, pp. 11211126.

[11]Boettcher, J. V. (2007). Ten core principles for designing effective learning environments: Insights from brain research and pedagogical theory. Innovate: Journal of Online Education, 3(3), n3.

[12] S. J Ball, "Mixed- Ability teaching: the worksheet method," British Journal of Engineering and Technology, 1980, page: $36-48$. 